\title{
HACIA UNA INFRAESTRUCTURA DE DATOS ESPACIALES ARQUEOLÓGICA. GEOPORTAL DE LA EXCAVACIÓN ARQUEOLÓGICA DE GEOKTCHIK-DEPE, TURKMENISTÁN
}

\author{
Óscar Luis Miguel Castro (Centro Geográfico del ET) \\ Teresa Fernández Pareja (Universidad Politécnica de Madrid)
}

\begin{abstract}
Several years have passed since the publication of the regulations INSPIRE (Infrastructure for Spatial Information in the European Community) and its transposition into Spanish law. So far, there is no fully harmonized geoportal to INSPIRE archaeological information. This is due in part to the lack of a profile of the application schema adapted to archaeological data. This article describes the process for the preparation of a geoportal with access to data from an archaeological excavation according to the draft of schema "INSPIRE Cultural Heritage Data" compiled by the CSIC (Consejo Superior de Investigaciones Científicas) and its associated services. The aim is to structure the information in a way enabling both interoperability and understanding of it, being accessible through standardized services ${ }^{1}$. All this applied to the site of Geoktchik-depe, Turkmenistan.
\end{abstract}

\section{KEYWORDS}

INSPIRE, Spatial Data Infrastructure, Geoktchik-depe, geoportal.

\section{RESUMEN}

Varios años han transcurrido desde la publicación de la normativa INSPIRE (Infrastructure for Spatial Information in the European Community) y su transposición a la legislación española, sin que exista, hasta el momento, ningún geoportal de información arqueológica completamente armonizado con INSPIRE, debido en parte a la falta de un perfil del esquema de aplicación adaptado a los datos arqueológicos. En este artículo se presenta el proceso para la confección de un geoportal con acceso a datos de una excavación arqueológica según el borrador de esquema INSPIRE Cultural Heritage Data confeccionado por el CSIC (Consejo Superior de Investigaciones Científicas), así como sus servicios asociados, con la finalidad de estructurar la información de manera adecuada permitiendo tanto la interoperabilidad como la comprensión de la misma, siendo accesible a través de unos servicios normalizados ${ }^{1}$. Todo ello aplicado a la excavación arqueológica de Geoktchik-depe, Turkmenistán.

\section{PALABRAS CLAVE}

INSPIRE, Infraestructura de Datos Espaciales, Geoktchik-depe, geoportal.

\section{Introducción}

El origen de este estudio nace del ofrecimiento del Prof. Dr. Joaquín María Córdoba Zoilo para participar en el Grupo de Investigación que coordina, durante las excavaciones en el yacimiento de Geoktchik-depe, Turkmenistán. El objetivo principal de este trabajo es proporcionar las directrices para la configuración y puesta en marcha de un geoportal piloto que muestre, según los esquemas de aplicación y formatos recogidos en la iniciativa

\footnotetext{
1 Infraestructura de Datos Espaciales de España. Grupo de Trabajo de Patrimonio Histórico (GTT-PAH). Modelo de datos de Patrimonio Histórico como Lugares Protegidos de INSPIRE v 2.1. (2011). Consejo Superior Geográfico.
} 
INSPIRE y borradores propuestos para datos arqueológicos, los datos estructurados de una excavación arqueológica con una triple finalidad ${ }^{2}$ :

- Que el equipo de investigación que continúe con los trabajos de excavación pueda extraer o completar la información de una manera lógica y estructurada según unos estándares definidos, asegurando la interoperabilidad y la inteligibilidad de la información.

- Que el geoportal sea en un futuro un canal de difusión de esa información hacia el público en general, ofreciendo información adecuada de una manera sencilla y hacia un usuario genérico interesado en temas arqueológicos.

- Que la puesta en marcha de manera práctica de un geoportal piloto permita extraer las conclusiones pertinentes respecto a la aplicación práctica de los esquemas de aplicación INSPIRE.

Fruto del ofrecimiento del Prof. Dr. Joaquín María Córdoba Zoilo y del estudio previo de la documentación aportada, se decidió ordenar y completar dicha documentación con la que se obtuviera de la campaña sobre el terreno con el fin de organizarla y formatearla adecuadamente para proporcionar una información correctamente estructurada e interoperable, capaz de satisfacer las necesidades de información, tanto de futuros investigadores como del público en general interesado por la Historia antigua ${ }^{4}{ }^{6}$. En la Figura 1 se presenta la localización geográfica de Geoktchik-depe.

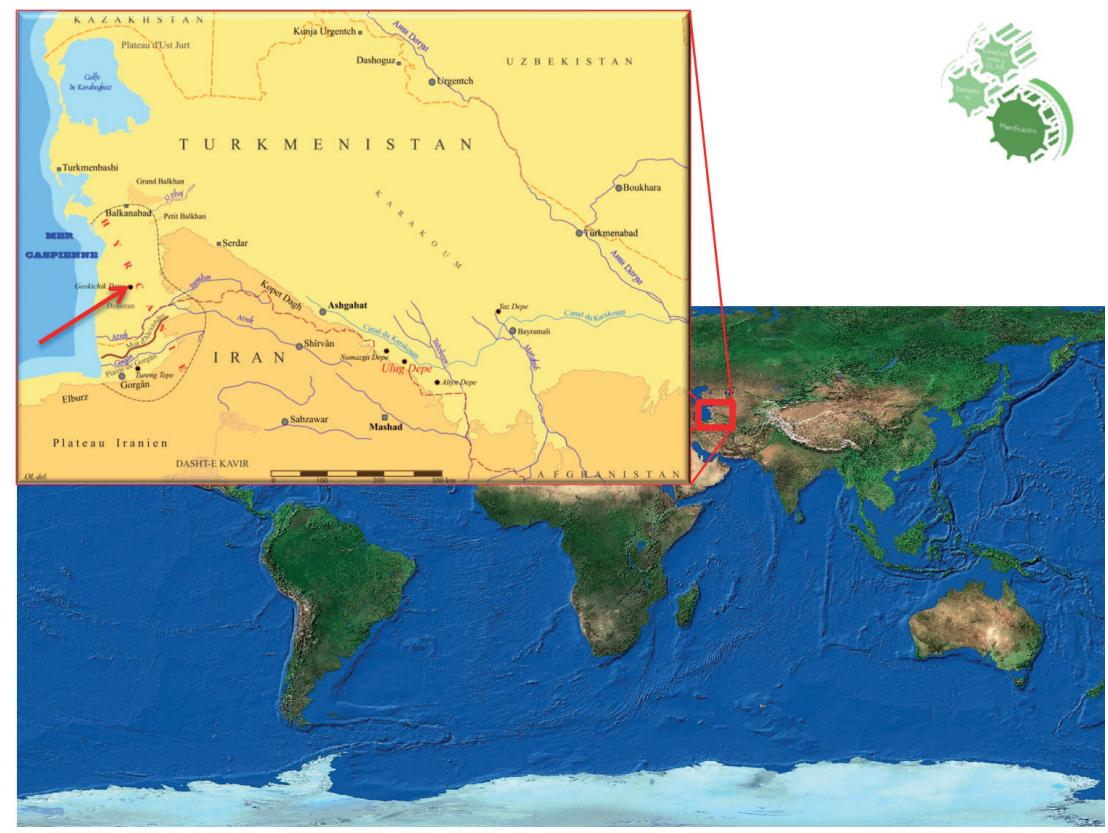

fig. 1. Localización Geográfica

\footnotetext{
2 Fernández Freire, C.; Pérez Asensio, E.; Del Bosque González, I. et al., 2012, "Proposal for a Cultural Heritage Application Schema within the INSPIRE directive. Multidisciplinary Research on Geographical Information in Europe and Beyond". Proceedings of the AGILE'2012 International Conference on Geographic Information Science. Avignon,. 24-27 April 2012. ISBN: 978-90-816960-0-5.

3 Fernández Freire, C.; Del Bosque González, I.; Vicent García, J. M. et al., 2012, “A guide for the interoperability of Cultural Heritage Data in INSPIRE". INSPIRE Conference. Estambul, 23-27 de June 2012.

4 Córdoba, J. M., "Hircania y la llanura olvidada. Estudios y excavaciones arqueológicas hispano-turkmenas en Dehistán", Eurasiática ${ }^{\circ} 2$ 2. Revista online sobre Asia Central. https://sumolok.com/hircania-y-la-llanuraolvidada/ Último acceso el 19 de julio de 2019.

5 Lecomte, O., 2009, " Origine des cultures agricoles du Dehistan (Sud-Ouest Turkménistan) Mise en oeuvre et gestion de l'irrigation de l'âge du Fer à la période islamique", Bibliothèque archéologique et historique 186, pp. 69-77. http://ifpo.revues.org/1295. Beirut Press IFPO. Último acceso el 19 de julio de 2019.

6 www.uam.es/otroscentros/asiriologiayegipto/publicaciones/ Último acceso el 11 de julio de 2019.
} 
Este proyecto fue acometido tomando como origen los datos de las campañas realizadas entre 1994 y 1997 por el equipo del Prof. Dr. Olivier Lecomte, director del primer proyecto en Geoktchik-depe, en el marco de la Misión Franco-Turkmena.

\section{Selección del modelo de datos INSPIRE}

El término Infraestructura de Datos Espaciales (IDE) aúna la acumulación de tecnologías, normas y acuerdos institucionales que facilitan el acceso a los datos espaciales. Esta definición requiere un marco normativo y tecnológico que posibilite la gestión, integración, armonización y distribución de grandes volúmenes de información geográfica de referencia, temática o con una componente temporal ${ }^{7}$.

La directiva 2007/2 de la Unión Europea INSPIRE establece la creación de una IDE común europea con el objetivo de asegurar la interoperabilidad y puesta en común de una serie de datos geográficos y servicios asociados, relacionados principalmente con aspectos medioambientales en el ámbito de la Unión Europea ${ }^{8}$.

La aprobación de la directiva y su transposición a la legislación española mediante la Ley 14/2010 de 5 de julio es el punto de inicio para un esfuerzo cooperativo de desarrollo y adecuación de información geográfica e implementación de servicios de datos espaciales, fundamentalmente en el ámbito de las Administraciones Públicas, pero con la inestimable colaboración de Universidades, Centros de Investigación y empresas privadas.

Por otro lado, el Patrimonio Cultural está formado por un conjunto de elementos, materiales e inmateriales, que cada sociedad reconoce como propios e idiosincráticos $\mathrm{y}$, como tales, merecedores de una protección legal Esta definición incluye elementos procedentes del pasado relacionados con el devenir histórico, elementos monumentales de valor artístico singular, objetos arqueológicos, arquitecturas populares, etc., e incluso realidades mucho más amplias, por ejemplo regiones o paisajes, o elementos que se podrían caracterizar como inmateriales, por ejemplo tradiciones, usos, costumbres y lenguajes. La dimensión espacial y geográfica es fundamental para gestionar el Patrimonio Cultural, pues los elementos que lo componen se localizan en espacios determinados que, en muchos casos, son parte esencial del patrimonio.

Todo lo anterior significa que en gran medida, y aún dentro de una singularidad propia, el Patrimonio Cultural es información geográfica y como tal, es posible considerar al Patrimonio como algo susceptible de ser representado, administrado, analizado y difundido a través de una IDE. Pero además el Patrimonio, en la medida en la que se constituye en forma de lugares protegidos, conforma una categoría de datos geográficos de importancia esencial no sólo en sí mismos, sino en relación con otros y dentro de las políticas de ordenación y planificación del medio, de gestión ambiental y de desarrollo local o turístico. Por esta razón resulta fundamental que esta información se integre dentro de una política de interoperabilidad geoespacial ${ }^{9}$.

Si bien el yacimiento arqueológico Geoktchik-depe no pertenece al espacio de la Unión Europea, los créditos y recursos aportados, tanto en las campañas anteriores realizadas en el marco de la Misión Franco-Turkmena como de las presentes y futuras que realice el Prof. Dr. Córdoba y su equipo, sí lo son. Por tanto, la obtención de esa información, sufragada con los recursos de los contribuyentes, bien merece su puesta a disposición de los mismos; la herramienta por excelencia para poner a disposición de los ciudadanos la información geoespacial generada es la Infraestructura de Datos Espaciales.

\footnotetext{
7 Infraestructura de Datos Espaciales de España. Núcleo Español de Metadatos v.1.2. (Versión final). Consejo Superior Geográfico.

8 http://www.idee.es/resources/documentos/NEMv1.2.pdf Último acceso el 11 de julio de 2019.

9 Carve, F., Fábrega-Álvarez, P. y otros, 2010, "Integración del patrimonio cultural en las infraestructuras de datos espaciales", I Congreso Uruguayo de Infraestructuras de Datos Espaciales.
} 
Otro motivo para la elección de INSPIRE es su extremada complejidad. Desde 2007, año en el que se establece la directiva, pocos conjuntos de datos en el ámbito europeo siguen fielmente las especificaciones que, a partir de ese año, se han ido emitiendo. Los trabajos de adecuación y transformación de los modelos de datos de los organismos productores de información geoespacial europeos se ven retrasados en numerosas ocasiones por la dificultad de adaptación al modelo. Igualmente sucede con los datos arqueológicos. El reto de este proyecto reside en aplicar prácticamente un borrador de esquema conforme con las especificaciones INSPIRE, todavía en desarrollo y que tiene algunas lagunas que impiden su completa integración en las mismas.

Aunque existen algunos ejemplos de servicios de datos espaciales relacionados con la arqueología, como el proyecto SILEX de IDE arqueológica del yacimiento de Casa Montero o el proyecto IDE de paisajes culturales de Las Médulas, ninguno de ellos es realmente conforme a las especificaciones en vigor para la capa Protected Sites del Anexo I de INSPIRE, lugar donde se recoge la estructura y modelo de datos para almacenar información espacial relativa a datos arqueológicos considerados como patrimonio histórico ${ }^{10} 1112$.

\section{Desarrollo}

El diseño de la infraestructura que se propone incluiría las siguientes actividades:

- Estudio y filtrado de los datos de la excavación realizada por el Prof. Dr. Olivier Lecomte entre 1994 y 1997 para su adaptación al modelo de datos y especificaciones INSPIRE con la mínima pérdida de información.

- Diseño de una Base de Datos según el esquema de aplicación INSPIRE Protected Sites y borrador INSPIRE Cultural Heritage Data.

- Extracción, transformación y carga de datos arqueológicos en la base de datos.

- Confección y carga de metadatos conforme al Núcleo Español de Metadatos.

- Configuración de un servicio web de mapas según la especificación INSPIRE.

- Configuración y publicación de un servicio web de catálogo con los metadatos de servicios y datos de la excavación según el estándar CSW (Catalogue Service for the Web) de OGC (Open Geospatial Consortium) ${ }^{13}$.

- Configuración del geoportal.

\subsection{Estudio y adecuación de los datos de partida}

El objetivo de esta fase es lograr la conversión de formatos físicos de archivos originales de información a formatos actuales y extendidos, tanto de base de datos como de información geográfica. Una vez lograda la transformación, se estudian los datos y su tipología para lograr el encaje con los modelos de datos Protected Sites de INSPIRE y el borrador del modelo Cultural Heritage Data.

La documentación aportada por el equipo de investigación del Prof. Dr. Joaquín María Córdoba de la Universidad Autónoma de Madrid, que provenía del equipo de investigación del Prof. Dr. Olivier Lecomte, se puede dividir en dos elementos característicos: documentación en papel y archivos digitales.

\footnotetext{
10 www.casamontero.org Último acceso el 11 de julio de 2019.

11 https://terraeantiqvae.com/m/blogpost?id=2043782\%3ABlogPost\%3A46477 Último acceso el 11 de julio de 2019.

12 Fraguas, A., Menchero, A. y otros, 2010, "Spatial Data Infrastructures and Archaeological Excavation Data: SILEX, the SDI of the Neolithic Flint Mine of Casa Montero (Madrid, Spain)", Fusion of Cultures. Abstracts of the XXXVIII Annual Conference on Computer Applications and Quantitative Methods in Archaeology, pp 63-66. CAA2010.ISBN: 978-84-693-0772-4.

13 www.opengeospatial.org Último acceso el 11 de julio de 2019.
} 
Dicha información corresponde a las excavaciones realizadas en los enclaves turkmenos Geoktchik-depe, Misrian y Tchahar Bagh. Los documentos aportados constituyen un conjunto heterogéneo de datos sin orden cronológico.

La documentación en papel es en muchos casos ininteligible al tratarse de fotocopias de fotocopias de croquis realizados en la excavación, no pudiéndose distinguir lo que el autor escribió sobre ellos. En cuanto a la documentación en formato digital, adolece de los mismos defectos que su homónima en papel, incrementados por la codificación y tratamiento original en formatos usados por software que actualmente no se utiliza, o cuyas versiones no son compatibles. Sin embargo, el interés demostrado por el equipo de investigación dirigido por el Prof. Dr. Córdoba por la obtención de una correcta representación cartográfica de los elementos del yacimiento, así como la transformación de datos a un formato organizado e interoperable, hacen de estas dificultades un reto a asumir. Ver Figura 2.
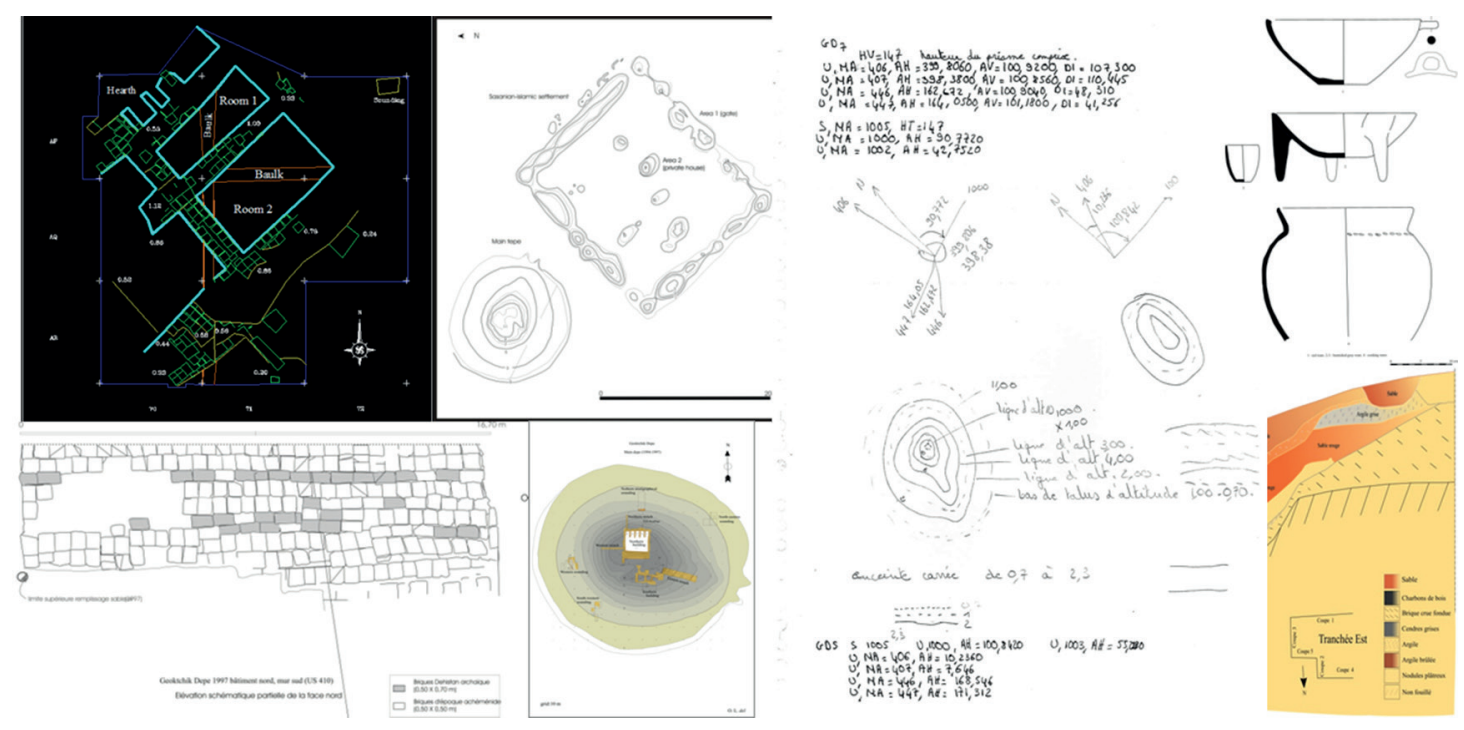

fig. 2. Documentación inicial

Una vez analizados los datos de partida, se adaptan al modelo de la siguiente forma:

- Yacimiento de Geoktchik-depe: Clase ProtectedSite del modelo INSPIRE. Es un yacimiento protegido por las leyes de la República de Turkmenistán como yacimiento arqueológico e incluido en la World Heritage Convention de la UNESCO.

- Recintos Sasánido-Islámicos y Dehistán Arcaicos como ProtectedHeritagePlace del modelo Cultural Heritage Data. Son lugares con entidad y características propias dentro del yacimiento genérico.

- Edificaciones de manera individual dentro de cada recinto como CulturalEntity del modelo Cultural Heritage Data.

- El resto de elementos que componen cada edificación tienen correspondencia en la clase HumanMadeObject del modelo Cultural Heritage Data. Son elementos constructivos de los edificios, manufacturados a su vez a partir de otros elementos simples (roca, piedra, adobe, mampostería, arena, etc.).

- Elementos cerámicos y objetos realzados o modificados por la mano del hombre: HumanMadeFeature del modelo Cultural Heritage Data.

- Elementos naturales encontrados en el yacimiento: NaturalFeature del modelo Cultural Heritage Data. 
3.2 Configuración de una base de datos

El núcleo de cualquier IDE, al igual que el de cualquier otro SIG (Sistema de Información Geográfica), lo conforma la base de datos donde se alojará toda la información espacial y alfanumérica asociada a los fenómenos geográficos que representan la realidad espacial.

La configuración de la base de datos que alojará los datos arqueológicos con características espaciales comienza con la instalación del propio software de base de datos y su extensión espacial. La base de datos escogida, por su relación coste-calidad, así como apoyo de la comunidad y documentación disponible es PostgreSQL 9.0 con la extensión espacial PostGIS 1.5. Con ello, y al ser software libre, el proyecto cumple con la recomendación europea que dicta que "El Marco Europeo de Interoperabilidad se basará en normas abiertas y fomentará el uso de programas de fuente abierta" (Plan de Acción eEurope 2005).

La configuración y creación de las distintas tablas que alojarán los datos se realiza tomando el modelo UML (Unified Modeling Languaje) y los esquemas de aplicación de la capa Protected Sites y Cultural Heritage Data, modelando una tabla para cada fenómeno según el esquema. Las relaciones entre tablas se realizan directamente mediante los campos RID, que relacionan la tupla correspondiente con el identificador único IFCID del objeto relacionado. El motivo fundamental de la selección de esta solución, puesto que los elementos pueden tener relaciones múltiples, es evitar la complicación de tablas específicas de relación, aunque existan campos vacíos en algunas tablas. Así mismo, se modelan las tablas que alojarán atributos complejos. Dichas tablas se modelan según el esquema de aplicación Protected Sites y Cultural Heritage Data.

\subsection{Extracción, transformación y carga de datos en la base de datos arqueológicos}

Esta fase corresponde al modelado de los datos recogidos durante las campañas de excavación arqueológica para su adaptación al modelo de datos INSPIRE y al borrador del modelo Cultural Heritage Data, como extensión del mismo.

Para el modelado de datos, se ha usado el sistema de información geográfica ArcGis. El motivo de emplear este SIG se debe a sus capacidades y funcionalidad contrastada.

El sistema de referencia espacial plantea el primer problema en la fase de modelado de datos del proyecto. INSPIRE, en su Specification on Coordinate Reference SystemsGuidelines, indica que el sistema de referencia será el ETRS 89 (European Terrestrial Reference System). Sin embargo, el empleo de este sistema sólo tiene sentido en zonas de la placa continental europea. Así mismo, la especificación define que fuera de esta área se empleará un sistema conforme a las especificaciones ITRS (International Terrestrial Reference System). Por tanto, se escoge este sistema como sistema de referencia para los datos del proyecto, llevando asociado el WGS 84 (World Geodetic System) que es el sistema de referencia de multitud de datos de intercambio y disponibles en la red. En una próxima publicación se tratará cómo documentar gráficamente un yacimiento arqueológico y se puntualizará sobre los sistemas y marcos de referencia globales.

Sin embargo, los datos originales (mapas, croquis, datos arqueológicos vectoriales, imágenes y fotografías) están referidos a diferentes sistemas de coordenadas locales sin correspondencia con un sistema global de coordenadas. Este hecho implica realizar el proceso denominado georreferenciación, es decir, efectuar la transformación de los sistemas de referencia local de los datos originales al sistema global WGS 84. La georreferenciación de los datos se considera fundamental para documentar espacialmente un yacimiento.

Los datos arqueológicos correspondientes, tanto las clases con geometría asociada, como las clases que no tienen representación espacial, así como las clases que son atributos complejos de otras, se cargan directamente en la base de datos PostgreSQL mediante la 
herramienta "PostGis shape and dbf loader". Para ello, se han exportado del formato propietario de ArcGis a formato shapefile.

Las relaciones determinadas en el modelo se establecen en base a consultas SQL en la base de datos. Dichas consultas se almacenan internamente en forma de vistas, con lo cual el sistema de relaciones se mantiene independiente al cliente elegido para atacar la base de datos. Mediante estas consultas se crean las vistas específicas de las clases que posteriormente se servirán a través de un servicio web de mapas.

\subsection{Confección y carga de metadatos}

El catálogo es el medio por el cual se hacen accesibles los datos servidos por una IDE conforme a una serie de normas y especificaciones que forman parte de la misma. La base de esos catálogos son un conjunto de registros de metadatos que describen el contenido, calidad, condición, accesibilidad y otras características de los datos y servicios disponibles a través de las IDEs. Los metadatos INSPIRE están regulados por la especificación INSPIRE Metadata Implementing Rules y regula en su núcleo la composición y características de los metadatos, así como su codificación a nivel de conjunto de datos, series y servicios.

Como herramienta para la confección de metadatos, siguiendo el esquema general del proyecto, se escoge el software de libre distribución CatMDEdit. Este software está suficientemente probado, es fiable y tiene la garantía de instituciones oficiales que han colaborado en su desarrollo, además del soporte de una gran comunidad de usuarios.

CatMDEdit permite confeccionar y validar los metadatos de información tabulada en la base de datos no espacial, los metadatos de información geográfica y los metadatos de documentos e imágenes, pasando por todos ellos el test de conformidad de INSPIRE vía web.

\subsection{Configuración y publicación de un servicio web de mapas}

La configuración del servicio de mapas se realiza sobre el software Geoserver. Geoserver permite ofrecer múltiples servicios web estándar OGC, como Web Map Service, Web Feature Service, Style Layer Descriptor, Web Coverage Service y Web Processing Service. Geoserver es la implementación de referencia de Open Geospatial Consortium, y junto con su distribución se proporciona, entre otros plugins disponibles, la extensión del software para la generación de servicios de visualización INSPIRE como perfil WMS 1.3.0.

Como parte de la publicación del servicio de mapas se encuentra la simbolización gráfica de los elementos y datos que formarán parte de los mismos.

3.6 Configuración y publicación de un servicio web de catálogo con los metadatos de servicio y datos de la excavación

Para configurar el servicio de catálogo CSW se escoge el software de libre acceso y código abierto Geonetwork Opensource; es una aplicación de catálogo para la administración de metadatos de recursos georreferenciados que proporciona un interfaz para la búsqueda de datos geográficos a partir de la descripción almacenada en el catálogo correspondiente, así como la integración del visor del servicio de mapas en el propio interfaz de búsqueda.

Tras la configuración del servicio y base de datos asociada, se cargan los metadatos confeccionados conformes a las especificaciones. Por último, se personalizan tanto el interfaz de la aplicación como las imágenes y vistas en miniatura de referencia de los metadatos para la puesta definitiva del catálogo a disposición del público, mediante el propio interfaz de la aplicación o mediante peticiones estándar al servicio CSW. Ver la Figura 3. 


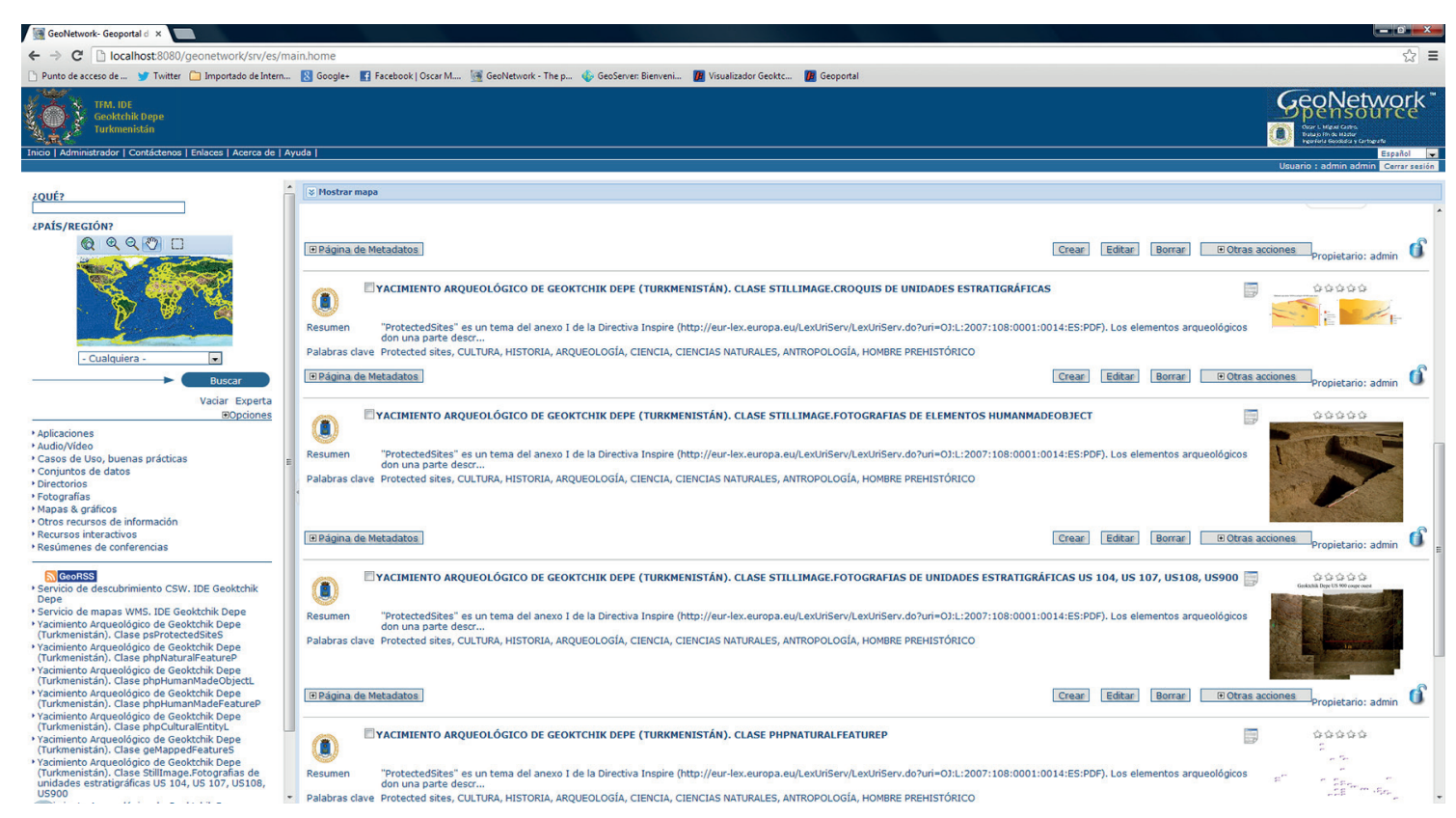

fig. 3. Publicación del servicio de catálogo

\subsection{Configuración del geoportal}

El geoportal es la herramienta puesta a disposición del público para el acceso a los datos y servicios de la infraestructura. Así mismo, y dentro de este proyecto, representa la sub-fase de desarrollo propiamente dicha, siendo necesario el desarrollo y la programación de líneas de código; en el resto de sub-fases las acciones de programación se circunscriben a la adecuación de software y configuración de archivos.

Dentro del amplio abanico de opciones para la configuración de un geoportal y cliente web, se escoge OpenLayers. OpenLayers es una librería JavaScript de uso libre bajo licencia Berkeley Software Distribution (BSD) para acceder, manipular y mostrar mapas en páginas web con independencia del navegador. OpenLayers proporciona un Application Programming Interface (API) que permite la creación de clientes web para acceder y manipular información geográfica proveniente de muy variadas fuentes, tanto OGC como propietarias (Google Maps, Bing, OpenStreetMap, etc.), lo que da una gran amplitud y flexibilidad. Para los desarrolladores existe otra ventaja: la comunidad de usuarios es bastante amplia, existiendo una buena documentación accesible por internet, además, sigue siendo un API en desarrollo, con lo que el futuro inmediato está asegurado.

El cliente de servicio de mapas se desarrolla en torno a una ventana interactiva de mapa, en la cual se cargan las capas servidas mediante el servicio de mapas de la infraestructura. Posteriormente se va desarrollando el resto de la aplicación en base a los requisitos y funcionalidad prevista, corrigiendo errores hasta ser completamente funcional. Dicha funcionalidad permite, entre otras, la consulta de la información alfanumérica de los elementos, a través de peticiones Asynchronous JavaScript And XML (AJAX) transparentes al usuario, mostradas en el panel inferior de información de la aplicación. Así mismo, la información está enlazada a una carpeta de archivos servida por el contenedor de aplicaciones, lo cual permite que las imágenes, croquis y demás documentación referenciada en los datos alfanuméricos sean accesibles a través de la web, y visibles para el cliente. Ver la Figura 4. 


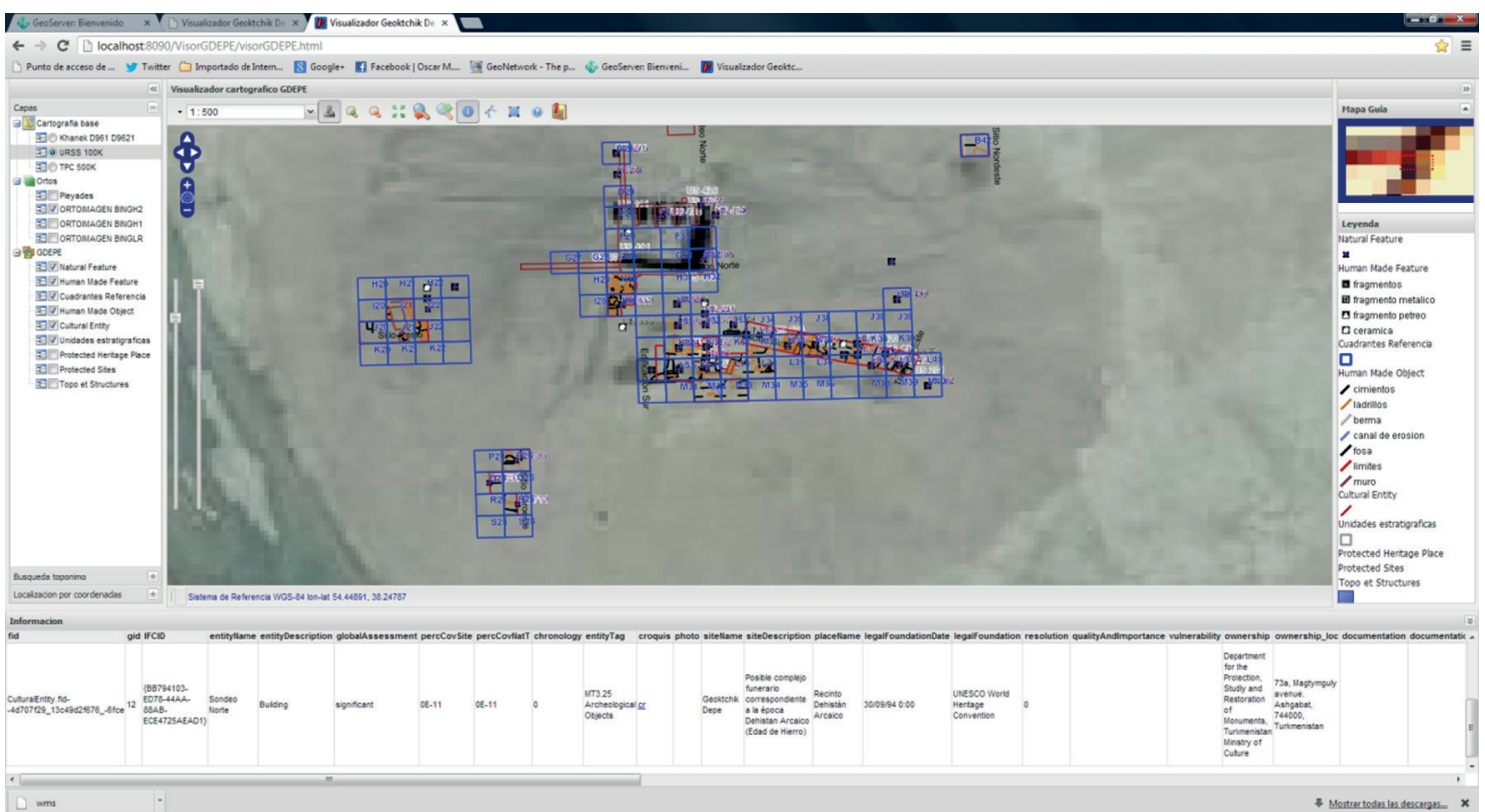

fig. 4. Visualizador de cartografía

Finalmente, se confecciona una página de presentación al geoportal con todos los elementos enlazados, sirviendo como plataforma de acceso a los servicios y donde en un sistema en producción, puede proporcionar acceso a otro tipo de información y enlaces complementarios. Ver la Figura 5.

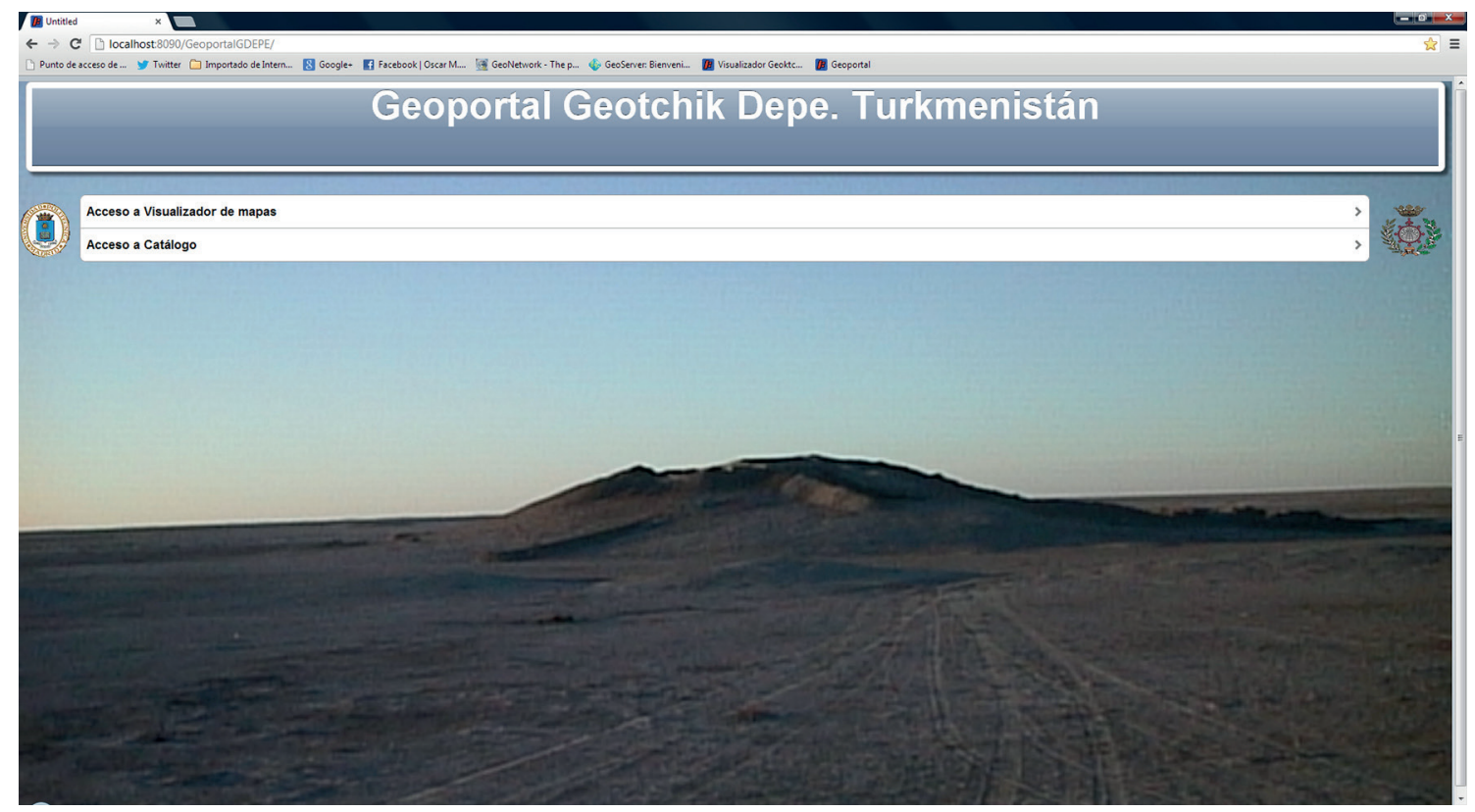

fig. 5. Página de presentación del geoportal Geotchik-depe

\section{Conclusiones}

Las conclusiones obtenidas una vez finalizado el proyecto piloto son numerosas y, debido a la extensión del mismo, presentan distintas características.

La conclusión esencial es la necesidad de emplear normas, estándares y una documentación adecuada y ordenada, tanto del material recogido en excavaciones arqueológicas como de los trabajos y proyectos posteriores realizados basados en ese material. La falta de uniformidad e inexactitud en la codificación de los datos y sus relaciones 
conlleva que haya existido una enorme dificultad en su interpretación, teniendo que desechar datos, bien por ininteligibilidad de los mismos, bien por falta de documentación necesaria para la adopción de fórmulas y procesos de transformación, o por corrupción de los propios archivos.

Por otra parte, la normativa INSPIRE empleada para modelar los datos arqueológicos como datos geoespaciales y los servicios de mapas y catálogo es de una considerable dificultad de aplicación. El modelo de datos es complicado de aplicar en una base de datos geoespacial. La posible existencia de atribución de tipo complejo y múltiple implica una enorme proliferación de tablas, relaciones, reglas y constreñimientos entre ellas, así como la dificultad añadida de su configuración.

Los modelos INSPIRE aparentemente están incompletos para la correcta y eficiente representación de la propia realidad, y exigen la derivación de perfiles y extensiones a los mismos. Poniendo como ejemplo el propio proyecto, el modelo INSPIRE Protected Sites está muy bien diseñado para la representación de información de lugares protegidos desde el punto de vista medioambiental, pero por su propia definición, debe dar cabida a datos del patrimonio cultural. Por ello es necesario un perfil, en este caso el borrador de esquema Cultural Heritage Data. Dicho esquema viene a completar una necesidad, pero es a su vez incompleto a la vista de las necesidades derivadas de la ejecución de este proyecto piloto, como por ejemplo la falta de una clase para modelar y relacionar los datos arqueológicos con las unidades estratigráficas, fundamentales para la datación de los hallazgos, siendo preciso completar este esquema y relacionarlo con otros, como el esquema Geology, para dar cabida a las necesidades de modelado de la información.

Finalmente se destaca el buen funcionamiento de las aplicaciones y API,s libres y de código abierto utilizadas para configurar los distintos servicios y el geoportal. Realmente son de una calidad extraordinaria, y existe una buena documentación y foros de usuarios y desarrolladores donde es posible apoyarse para lograr la correcta configuración y personalización de las aplicaciones y API,s libres.

\section{Referencias bibliográficas}

Carve, F., Fábrega-Álvarez, P. y otros, 2010, "Integración del patrimonio cultural en las infraestructuras de datos espaciales", I Congreso Uruguayo de Infraestructuras de Datos Espaciales.

Córdoba, J. M., "Hircania y la llanura olvidada. Estudios y excavaciones arqueológicas hispano-turkmenas en Dehistán", Eurasiática $n^{\circ} 2$. Revista online sobre Asia Central. https://sumolok.com/hircania-y-la-llanura-olvidada/ Último acceso el 19 de julio de 2019.

FernándezFreire, C.; PérezAsensio, E.; Del Bosque González, I. et al., 2012, "Proposal for a Cultural Heritage Application Schema within the INSPIRE directive. Multidisciplinary Research on Geographical Information in Europe and Beyond". Proceedings of the AGILE'2012 International Conference on Geographic Information Science. Avignon, 2427 April 2012. ISBN: 978-90-816960-0-5.

Fernández Freire, C.; Del Bosque González, I.; Vicent García, J. M. et al., 2012, “A guide for the interoperability of Cultural Heritage Data in INSPIRE". INSPIRE Conference. Estambul, 23-27 de June 2012.

Fraguas, A., Menchero, A. y otros, 2010, "Spatial Data Infrastructures and Archaeological Excavation Data: SILEX, the SDI of the Neolithic Flint Mine of Casa Montero (Madrid, Spain)", Fusion of Cultures. Abstracts of the XXXVIII Annual Conference on Computer Applications and Quantitative Methods in Archaeology, pp 63-66. CAA2010. ISBN: 978-84-693-0772-4.

Lecomte, O., 2009, « Origine des cultures agricoles du Dehistan (Sud-Ouest Turkménistan) Mise en oeuvre et gestion de l'irrigation de l'âge du Fer à la période 
islamique", Bibliothèque archéologique et historique 186, pp. 69-77. http://ifpo.revues. org/1295. Beirut Press IFPO. Último acceso el 19 de julio de 2019. 